\title{
Prisoners Educating Prisoners
}

Rob Rucier

$\mathrm{T}$ hree days after I arrived at SCI-Dallas in 1999, I became Clerk in the kitchen. One of my responsibilities was to process the paperwork necessary to give prisoner-workers their periodic pay raises. While doing so, I discovered that the Pennsylvania Department of Corrections had a rule in place that any prisoners with a reading level lower than the fifth grade could not receive a pay rate beyond twenty-four cents an hour. It was shocking to see that approximately fifteen percent of the kitchen workers had reading levels below this grade and were therefore functionally illiterate.

On my housing block, I was discussing this with Danny Graves (a tutor in the Laubach Literacy Program), who told me that, prison-wide, the illiteracy rate was even higher. He proceeded to tell me about the Laubach Program. I knew that I had to be involved, and I enrolled in the next tutor-training program. ${ }^{1}$

I was enthusiastic about Laubach because I agreed with many of the program's tenets.

- Repetition is used to help the student master the names and the sounds of letters. To avoid confusion, letters with multiple sounds are taught one sound at a time.

- Positive reinforcement is essential. The word "No" is not in the tutor's vocabulary.

- Privacy is strictly adhered to. Some students might be embarrassed if other prisoners found out that they had trouble reading and writing.

- "Each one teach one" is the program's motto. Having that one-on-one relationship with the student truly enhances his or her ability to learn.

- Moving at the student's own pace. This is a real benefit of the "each one teach one" concept.

I have been tutoring now for over two years and continue to be an enthusiastic disciple of this program. My frustration lies in the fact that we are only scratching the surface at this prison. We have about twenty-five to thirty students enrolled in the program at this time and there are probably ten times that many prisoners here who are functionally illiterate.

1 In late August 2002, the Laubach Literacy Program and Literacy Volunteers of America merged and are now called ProLiteracy Worldwide. 
At present, our primary problem is getting new prisoners to enroll in the Laubach Program. We have more tutors than students. The logical source for new students is the education department. However, there was a lack of support for the program from the department in the past. The Education Director and the teachers were reluctant to utilize the tutors. Fortunately, this is now changing. A new Education Director is very supportive of the program; therefore, it gets the teachers' support. In fact, we have been asked to speak to two introductory reading classes to encourage students to also enroll in the Laubach Program. This is a big step forward.

Another potential vehicle for encouraging new students to enroll is the use of a video. Danny Graves has written a script for a play about Laubach that would involve some of our students who are proud of the fact that they have learned to read and write. I suggested to him that we videotape his play and periodically show this tape on the in-house video channel. This strategy would reach a larger number of potential students and have a greater impact than written material that we could post on bulletin boards, a vehicle that has had no impact on attracting individuals to our program. There is no doubt that Laubach works. We simply need to sign up more students in order to make a deep dent in the illiteracy rate at this prison.

In June 2002, I became the President of our Laubach Executive Board. This position gives me a better chance to be an advocate for literacy programs of all types at SCI-Dallas. I believe that programs like Laubach are essential in the effort to reduce recidivism rates. In my estimation, the lack of education is one of the key contributing factors to ex-prisoners becoming prisoners again. I am not a penologist. I am a person who came to jail at age forty-six after being college educated and having worked for twenty-five years in the insurance industry. However, I do have definite opinions about the educational problems that exist here and in other prisons. I plan to spend my time working as much as possible to improve the education of all prisoners who are interested in bettering themselves, especially those being released soon.

In addition to being a Laubach Officer and tutor, I am also privileged to be Secretary of the newly-formed Education Committee of the SCI-Dallas Chapter of the Jaycee's. The first program we put in place (free of charge to prisoners and to the prison) was a creative writing class. This will teach prisoners how to write effective communications to staff and family while they are incarcerated. It will also be a help to them when they communicate with prospective employers and others once they are released. 
Some other programs that are in our future plans are geared toward those prisoners who we hope will be released in twelve to eighteen months. We hope the administration will look favorably on these efforts. These programs are listed below.

\section{DRIVER EDUCATION}

When an individual is released and is going to work, or looking for employment, a driver's license will be a necessity. We plan to give them a head start by going through the driver's license booklet issued by the Department of Motor Vehicles and preparing them for the written test.

\section{INTERNET}

The Internet has become almost as important as television in people's dailly life on the street. Information is obtained, job openings are listed, resumes are sent out, cars are bought, and the list goes on. But prisoners who have been inside for six years or more have very little idea of what the Internet is, and no idea of how to use it. Prisoners at SCI-Dallas are not permitted to use the Internet.

We want to offer a class using software that simulates the Internet (on a $\mathrm{CD}-\mathrm{ROM}$ ) so we can teach prisoners what is available on the Internet as well as how to "surf the Net." This is another essential skill for our fellow prisoners to learn before they are released. It will increase their self-confidence and their comfort level.

\section{BASIC COOKING}

The majority of prisoners being released are probably not going to make much more than minimum wage. Eating out is expensive. We want to offer basic recipes that will help them live within a budget.

\section{Checkiook/budgeting}

I am taking college classes here to keep active. In an accounting class I took only four out of eleven other students had ever had a checkbook or lived on a budget. These are critical skills to be learned if released prisoners are to live on what they can earn legitimately. 


\section{AUTOMATED TELLER MACHINES (ATMS)/ NEW SELF-SERVE GAS PUMPS}

With the help of an instructional video or pictures that we can obtain from banks and gas companies, we hope to teach fellow prisoners how to use ATMs and the new gas pumps. In doing so, we strive to reduce significantly the stress and the possible embarrassment that released prisoners might experience when they need to use these machines for the first time out on the street.

\section{Conclusion}

Jaycee's and the Literacy Council are striving to create positive and productive ways to help our fellow prisoners when they are released. We want them to fit in, to feel that they are a part of life out there, not feel like life has "passed them by" while they were incarcerated.

Finally, for those individuals who will be here for a longer period of time, we hope to hold several seminars on investing options that would be available to prisoners with small monthly incomes.

In my view, education is the key to a successful life out on the street. Prisoners who are blessed with an education should reach out to help our fellow prisoners learn as much as they can. We need to encourage them to take whatever classes they can, including learning a trade that will help them find work. We should also be prepared to teach programs that are not offered by the prison system.

Some people believe that prisoners should simply be warehoused. I was one such person when I was on the outside. From first-hand experience, I now realize such thinking is not going to solve anything. People will only change when they are given the knowledge and skills they need to change their lives successfully and forever.

Rob Rucier was vice president of an insurance company, taught Sunday school, and coached Little League prior to his incarceration. Currently, he is in the sixth year of an 18-36 year sentence. His two sons, Matt and Chris, are his inspiration and what keeps him going. He can be reached at \#DT8226, SCIDallas, 1000 Follies Road, Dallas, PA 18612. 